\title{
Intradural lumbar radicular arteriovenous malformation mimicking perimedullary arteriovenous malformation of the conus medullaris: illustrative case
}

\author{
Izumi Koyanagi, MD, ${ }^{1}$ Yasuhiro Chiba, MD, ${ }^{1}$ Hiroyuki Imamura, MD, ${ }^{1}$ and Toshiya Osanai, MD ${ }^{2}$ \\ ${ }^{1}$ Department of Neurosurgery, Hokkaido Neurosurgical Memorial Hospital, Sapporo, Hokkaido, Japan; and ${ }^{2}$ Department of Neurosurgery, Hokkaido University, Hokkaido, \\ Sapporo, Japan
}

\begin{abstract}
BACKGROUND Intradural radicular arteriovenous malformation (AVM) of the cauda equina is a rare entity of spinal AVMs. Because of the specific arterial supply of the conus medullaris and cauda equina, AVMs in this area sometimes present with confusing radiological features.

OBSERVATIONS The authors reported a rare case of intradural radicular AVM arising from the lumbar posterior root. The patient presented with urinary symptoms with multiple flow void around the conus medullaris, as shown on magnetic resonance imaging. Digital subtraction angiography demonstrated arteriovenous shunt at the left side of the conus medullaris fed by the anterior spinal artery via anastomotic channel to the posterior spinal artery and rich perimedullary drainers. There was another arteriovenous shunt at the $L 3$ level from the left $L 4$ radicular artery. Preoperative diagnosis was perimedullary AVM with radicular arteriovenous fistula. Direct surgery with indocyanine green angiography revealed that the actual arteriovenous shunt was located at the left L4 posterior root. The AVM was successfully treated by coagulation of feeding branches.
\end{abstract}

LESSONS Unilateral arteriovenous shunt fed by either posterior or anterior spinal artery at the conus medullaris may include AVM of the cauda equina despite abundant perimedullary venous drainage. Careful pre- and intraoperative diagnostic imaging is necessary for appropriate treatment.

https://thejns.org/doi/abs/10.3171/CASE21551

KEYWORDS radicular arteriovenous malformation; cauda equina; conus medullaris; perimedullary arteriovenous malformation

Location of arteriovenous shunt determines clinical and radiological features of arteriovenous malformations (AVMs) in the spinal canal. It is known that spinal AVMs at or below the conus medullaris have some special clinical features ${ }^{1}$ because of specific anatomical characteristics, such as long course of the cauda equina and presence of arterial basket of the conus medullaris. ${ }^{2}$ Here, we report a case of intradural lumbar radicular AVM involving urinary symptoms. Preoperative imaging studies were suggestive of perimedullary AVM at the conus medullaris. Direct surgery revealed AVM at the left L4 posterior root. Intradural radicular AVM of the cauda equina is a rare entity with spinal AVMs. Radiological and intraoperative findings in this case will help to understand the pathophysiology and treatment of radicular AVM at the levels of the conus medullaris and cauda equina.

\section{Illustrative Case}

A male patient in his 40 s developed numbness and pain at the perianal region 6 months before admission. He had been treated for chronic prostatitis at the urology clinic for 10 years. Because of abnormal findings in the lower spinal cord on magnetic resonance imaging (MRI), he was referred to our hospital for further treatment. Neurological examination on admission to our hospital showed dysesthesia in the perianal region and bilateral legs. He also experienced frequent urination. MRI demonstrated abnormal flow void around the conus medullaris and cauda equina (Fig. $1 A$ and $B$ ). Computed tomography angiography showed enlarged vessels on the spinal cord surface at the T11- L1 levels and tortuous vessels extending to the $\mathrm{L} 3$ level in the left side of the spinal canal (Fig. $1 \mathrm{C}$ and D). Digital subtraction angiography (DSA) revealed that the

ABBREVIATIONS ASA = anterior spinal artery; AVM = arteriovenous malformation; DSA = digital subtraction angiography; ICGA = indocyanine green angiography; $\mathrm{MRI}=$ magnetic resonance imaging; PSA = posterior spinal artery.

INCLUDE WHEN CITING Published November 22, 2021; DOI: 10.3171/CASE21551.

SUBMITTED September 23, 2021. ACCEPTED October 7, 2021.

(C) 2021 The authors, CC BY-NC-ND 4.0 (http://creativecommons.org/licenses/by-nc-nd/4.0/). 

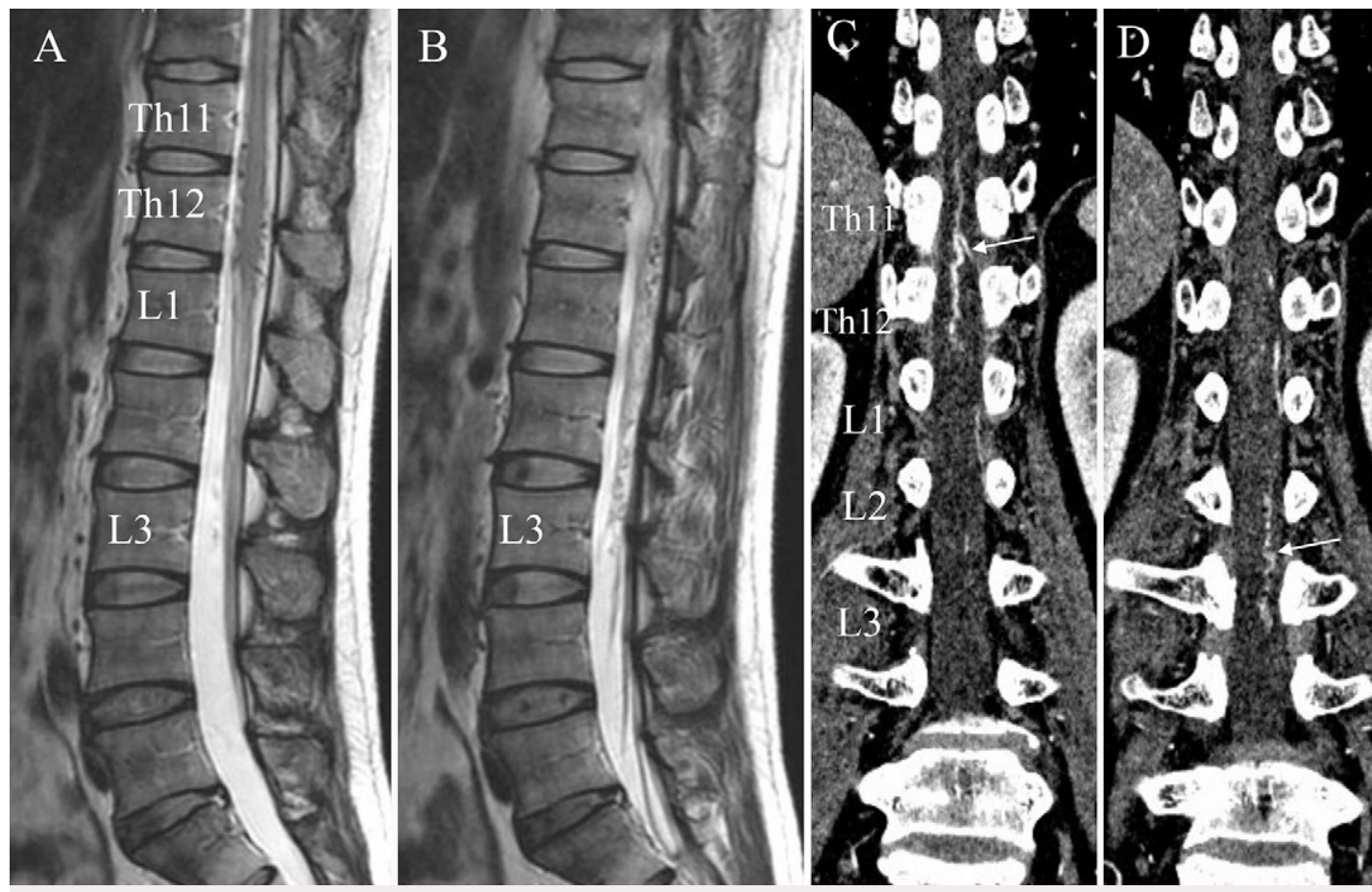

FIG. 1. Preoperative MRI (A and B) and computed tomography angiography ( $C$ and $\mathbf{D}$ ). A: T2-weighted sagittal image of the thoracolumbar spine showing abnormal flow void around the spinal cord at the T11-L1 levels. B: Sagittal image (slightly left to A) showing abnormal flow void extending to the L3 level. C: Coronal reconstruction of the thoracolumbar spine showing large anterior spinal vein branching a left radicular vein (arrow) at the T11-T12 level. D: Coronal reconstruction (slightly dorsal to $\mathrm{C}$ ) showing tortuous vessels at the L2-L3 levels (arrow)

anterior spinal artery (ASA), which branched from the left T9 intercostal artery, fed the abnormal vascularity of the left posterior spinal cord at T12-L1 levels via anastomosis with the posterior spinal artery (PSA) at the L1 level (Fig. 2). Draining venous channels were present at both the anterior and posterior spinal cord surfaces, and a large draining radicular vein from the anterior spinal cord surface at the T11-T12 level coursed caudally in the left spinal canal (Fig. 2). From the left $L 4$ radicular artery, which branched from the left internal iliac artery, there was another arteriovenous shunt at the L3 level. The abnormal tortuous venous channels continued along the left L4 root to the spinal cord level and drained finally into the left large radicular vein at the T11-T12 level (Fig. 3). From these findings, preoperative diagnosis was perimedullary AVM of the conus medullaris combined with lumbar radicular arteriovenous fistula.

Direct surgery was performed with the patient placed prone under general anesthesia. Laminectomies from T11 to the upper one-third of L2 and from the lower one-third of L2 to upper one-third of L4 were carried out to inspect the conus AVM and radicular arteriovenous fistula, respectively (Fig. 4). Upon opening the dura at L3, many tortuous vessels were visible in the cauda equina (Fig. 4D). Intraoperative indocyanine green angiography (ICGA) demonstrated a feeding artery from the left $L 4$ radicular artery (Fig. $4 \mathrm{E}$ ) and early filling of tortuous dilated veins (Fig. 4F). Although this feeding artery was coagulated and cut, early filling of the tortuous vessels was still present. The dura at T12-L1 then was opened. There were also many tortuous vessels on the dorsal surface of the conus medullaris and the left lumbar posterior root. The PSA arising from ASA was identified at the right side of the dorsal spinal cord. This PSA coursed to the left side and ran immediately ventral to the left posterior root with enlarged tortuous vessels (Fig. 4A). ICGA demonstrated that the PSA fed the abnormal vascularity of the posterior root (Fig. $4 B$ and C). Small arterial branches from the PSA were coagulated near the posterior root entry zone. Several arterial branches were also coagulated in the course of tortuous vascularity of the posterior root at the L1-L3 levels. Early filling of the abnormal vascularity disappeared on ICGA after these coagulating procedures. From these operative findings, we determined that this was the radicular AVM of the left posterior root, and perimedullary venous drainage produced conus medullaris symptoms.

The patient showed good recovery of sensory and urinary symptoms after surgery, although he developed temporary numbness and dysesthesia of the left leg. MRI 2 and 6 months after surgery demonstrated disappearance of abnormal flow void around the spinal cord (Fig. 4G). During follow-up at 10 months, there was no recurrence of symptoms.

\section{Discussion}

\section{Observations}

In this patient, arteriovenous shunt was located at the intradural left L4 posterior root. According to the literature, ${ }^{3}$ vascular supply of the intradural cauda equina was coming from pial arteries of the spinal cord and radicular arteries penetrating the dural sheath. The proximal one-third of the posterior root was supplied by arterial branches of the PSA and the distal two-thirds was fed by posterior radicular artery from the segmental artery. In this patient, because 


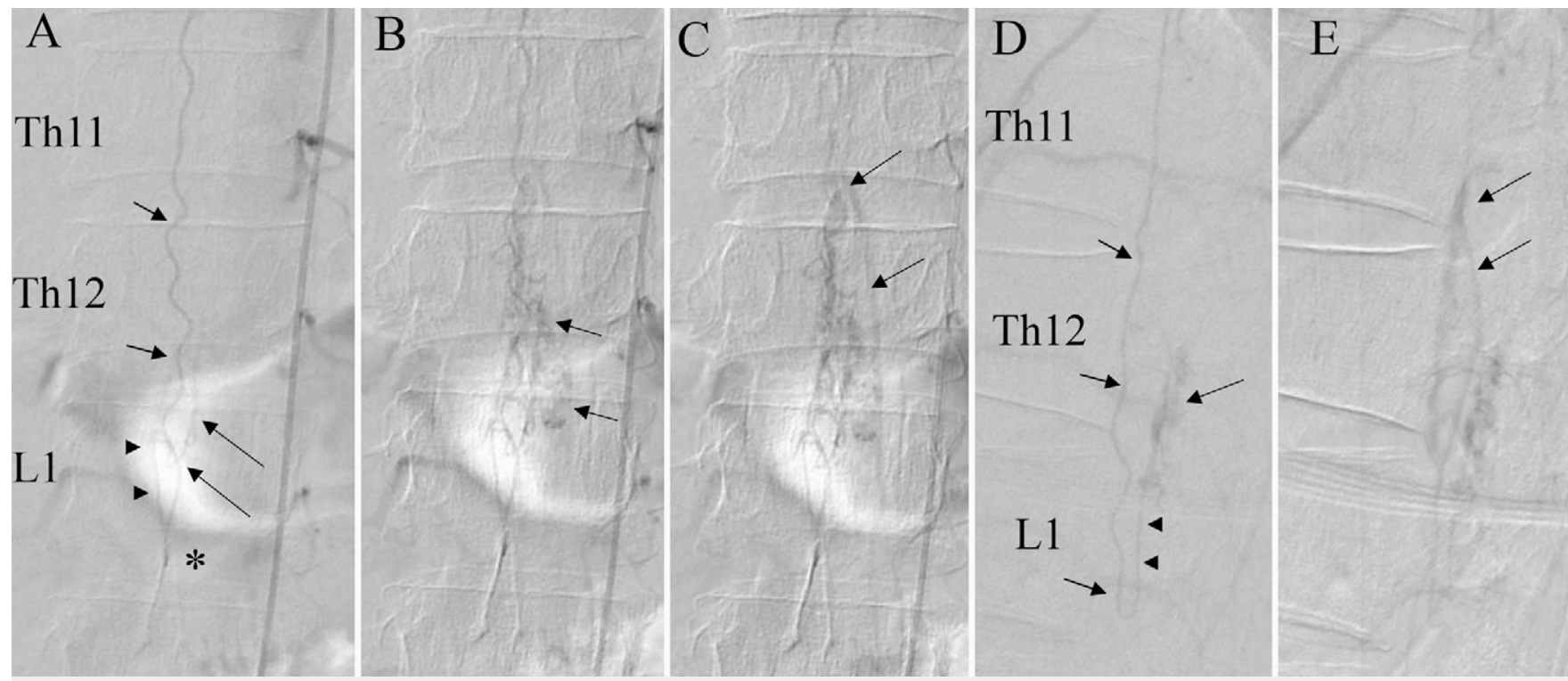

FIG. 2. Preoperative DSA by injection of the left T9 intercostal artery (A-C: anteroposterior view; D and E: lateral view). A: Arterial phase showing ASA coursing downward (small arrows) and then turning upward at the L1 level (asterisk) to the right PSA (arrowheads). The PSA courses to left and ascends at the left side of the spinal cord (long arrows). B: Late arterial phase showing abnormal vascularity at the left side of the spinal cord at the T12-L1 levels (arrows) and filling of the dilated veins over the spinal cord. C: Further late phase showing draining radicular vein (arrows) from the T11-T12 level. D: Lateral view of the arterial phase clearly showing the ASA (arrows), PSA (arrowheads), and early filling of abnormal vascularity (long arrow) from the PSA. E: Late phase showing abnormally dilated veins over the anterior and posterior spinal cord. A large draining vein (arrows) is originating from the anterior spinal cord at the T11-T12 level.

significant arteriovenous shunt occurred in approximately the rostral half of the L4 posterior root, pial arteries from the PSA and the radicular artery from the segmental artery entered the abnormal vasculatures of the posterior root. If arteriovenous shunt existed at the perimedullary region over the conus medullaris, more arterial channels from the vasa corona, such as lateral branches of the ASA or branches of the PSA

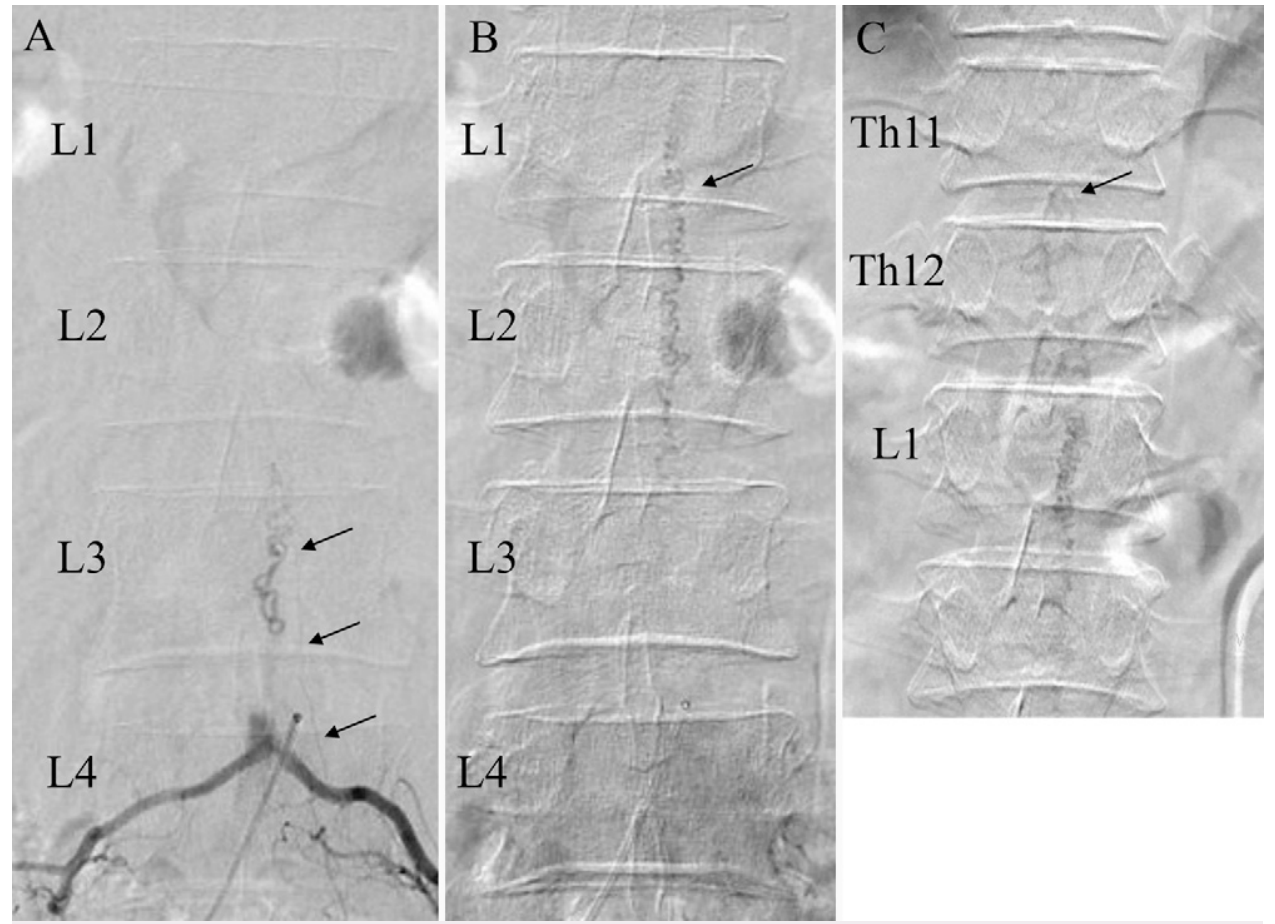

FIG. 3. Preoperative DSA by injection of internal iliac artery (anteroposterior view). A: Arterial phase showing left $L 4$ radicular artery (arrows) ascending in the spinal canal and feeding the tortuous enlarged veins at the $L 3$ level. B: Late phase demonstrating tortuous draining veins ascending to the L1 level (arrow). C: Further late phase showing continuation of drainers to the same left radicular draining vein (arrow) at the T11-T12 level. 

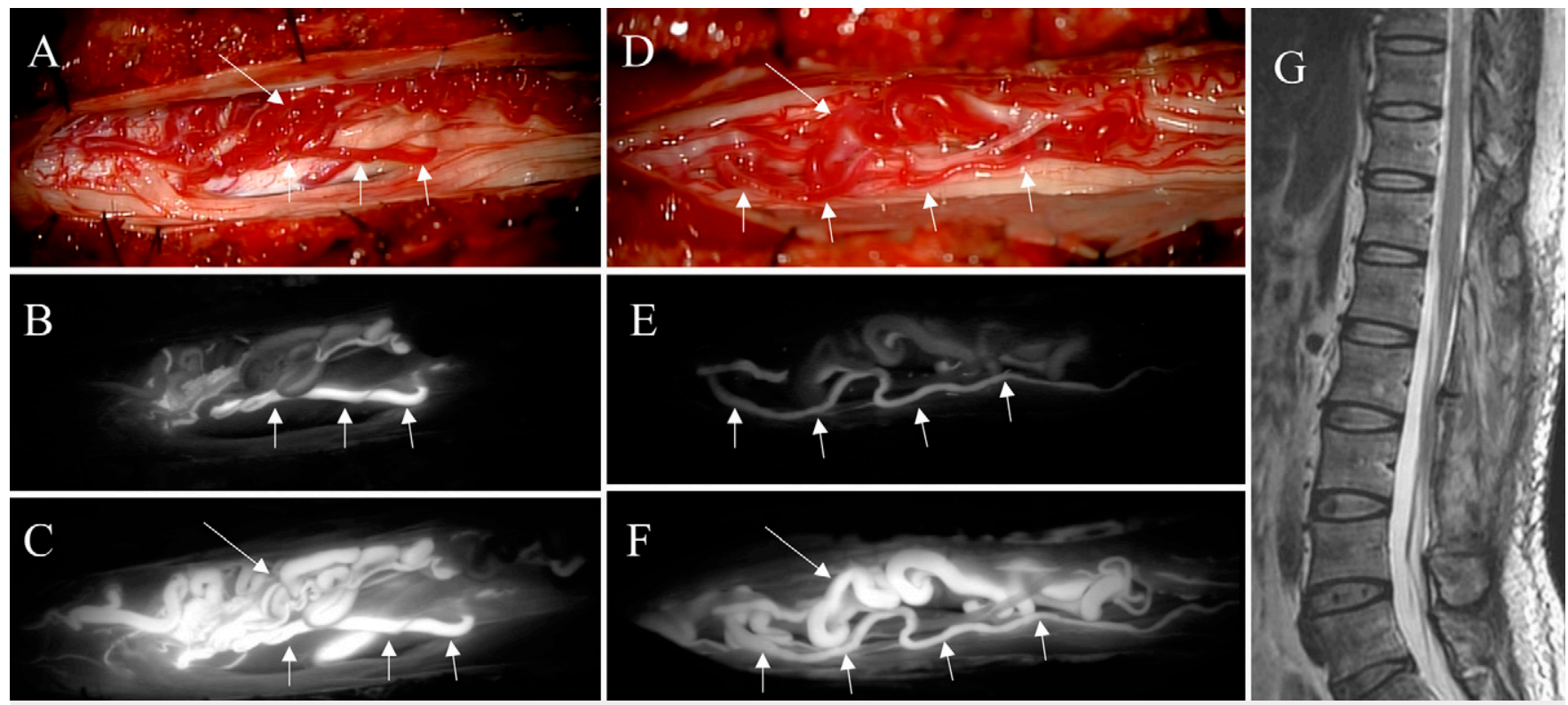

FIG. 4. Intraoperative view with ICGA (A-C: T12-L1 levels; D-F: L3 level; rostral is to the left) and postoperative MRI (G: T2-weighted sagittal image of thoracolumbar spine). A: After opening the dura at the T12-L1 levels. The left posterior root accompanied by large tortuous vessels (Iong arrow) is turned over to inspect dorsolateral side, where the PCA (arrows) traverses from right to left and courses rostrally just ventral to the left posterior root. B: ICGA demonstrating the PCA (arrows) as a main feeder. C: Late phase of ICGA showing the PSA (arrows) and early filling of large tortuous veins over the left posterior root (Iong arrow). D: After opening the dura at the L3 level. Large tortuous veins (Iong arrow) accompanying the L4 root and the L4 radicular artery (arrows) are identified. E: ICGA demonstrating the L4 radicular artery (arrows). F: Late phase of ICGA showing the L4 radicular artery (arrows) and early filling of large tortuous veins (long arrow) on the L4 root. G: MRI 2 months after surgery demonstrating disappearance of abnormal flow void around the spinal cord.

from other spinal levels, may have supplied the AVM. A relatively simple course of the main feeder from the ASA to PSA and feeding at the unilateral posterior side of the conus medullaris may indicate the posterior root as the actual shunting point.
There have been no large series regarding radicular AVMs or arteriovenous fistulae of the intradural cauda equina in the literature. To our knowledge, only 12 cases $^{1,4-6}$ were reported (Table 1). Feeding arteries were from the ASA (3 cases), segmental arteries

TABLE 1. Summary of 12 cases of intradural lumbar arteriovenous fistula or malformation reported in the literature

\begin{tabular}{|c|c|c|c|c|c|c|}
\hline Authors \& Yr & $\begin{array}{l}\text { No. of } \\
\text { Cases }\end{array}$ & Feeders & A-V Shunt Level & Drainers & Coexisting Lesions & Treatment \\
\hline \multirow[t]{2}{*}{$\begin{array}{l}\text { Hong et al., } \\
\qquad 2017^{1}\end{array}$} & 7 & $\begin{array}{l}\text { Radicular artery from the } \\
\text { lat sacral artery: } 7\end{array}$ & L5-S1 levels & $\begin{array}{l}\text { Radicular vein } \\
\text { draining to the } \\
\text { perimedullary veins }\end{array}$ & Conus AVM: 3 & $\begin{array}{l}\text { Endovascular: } 5 \text {; } \\
\text { direct surgery: } 1 \text {; } \\
\text { endovascular }+ \\
\text { direct surgery: } 1\end{array}$ \\
\hline & & & $\begin{array}{l}\text { Direct fistula: } 4 \\
\text { Micronidus-like } \\
\text { structure: } 3 \\
\end{array}$ & & & \\
\hline $\begin{array}{c}\text { Tanioka et al., } \\
2018^{4}\end{array}$ & 1 & ASA from It T9 & L2 level & $\begin{array}{l}\text { Ascending to the } \\
\text { perimedullary vein }\end{array}$ & - & Direct surgery \\
\hline $\begin{array}{l}\text { Namba et al., } \\
2020^{5}\end{array}$ & 2 & S1 radicular artery: 1 & L4 level: 1 & $\begin{array}{l}\text { Ascending vein to the } \\
\text { perimedullary vein: } \\
\text { 1; ascending vein to } \\
\text { the radicular vein: } 1\end{array}$ & $\begin{array}{l}\text { Conus perimedullary } \\
\text { AVF: } 1\end{array}$ & Not described \\
\hline $\begin{array}{l}\text { Ohtonari et al., } \\
2011^{6}\end{array}$ & 2 & $\begin{array}{c}\text { Radicular artery from } \\
\text { ASA: } 2\end{array}$ & Lumbar level: 2 & $\begin{array}{l}\text { Ascending vein to the } \\
\text { perimedullary vein: } 2\end{array}$ & - & Direct surgery: 2 \\
\hline
\end{tabular}

$\mathrm{AVF}=$ arteriovenous fistula. 
(8 cases), or both (1 case). Interestingly, all drainers ascended from the shunting point and entered into the perimedullary veins (11 cases) or radicular vein (1 case). Such venous drainage patterns were similar in our patient. It is likely that these patients developed clinical symptoms due to perimedullary venous hypertension and received neuroradiological examinations in clinical settings. If arteriovenous shunt is located at a more peripheral part of the cauda equina and venous drainage proceeds distally to the radicular vein, clinical symptoms may not be significant enough to visit clinics.

Of the reported 12 cases, 9 cases showed simple direct fistula and 3 cases had a micronidus-like structure. Four cases were associated with perimedullary AVM or arteriovenous fistula of the conus medullaris. Our patient also showed dilated vascular tangles over the conus medullaris. However, direct surgery with intraoperative ICGA revealed AVM of the L4 posterior root, not the perimedullary AVM. This case is the first to demonstrate extensive radicular AVM of the intradural cauda equina by ICGA. Considering the arterial supply patterns to the intradural cauda equina, unilaterally located shunting points at the conus medullaris either by tributaries of the PSA alone or ASA alone will indicate radicular AVM.

\section{Lessons}

Intradural radicular AVM of the cauda equina is a rare lesion and presents with confusing neuroradiological features. Arteriovenous shunt at the proximal half of the intradural cauda equina is fed by both pial arteries from the PSA or ASA and distal radicular artery. Unilateral feeding from either the PSA or ASA at the conus medullaris may include AVM of the posterior root or the anterior root despite abundant perimedullary venous drainage. Careful DSA examination and intraoperative imaging are important for diagnosis and treatment of radicular AVM in this area.

\section{References}

1. Hong T, Park JE, Ling F, et al. Comparison of 3 different types of spinal arteriovenous shunts below the conus in clinical presentation, radiologic findings, and outcomes. AJNR Am J Neuroradiol. 2017;38(2):403-409.
2. Martirosyan NL, Kalani MYS, Lemole GM Jr, Spetzler RF, Preul MC, Theodore N. Microsurgical anatomy of the arterial basket of the conus medullaris. J Neurosurg Spine. 2015;22(6):672-676.

3. Namba K. Vascular anatomy of the cauda equina and its implication on the vascular lesions in the caudal spinal structure. Neurol Med Chir (Tokyo). 2016;56(6):310-316.

4. Tanioka S, Toma N, Sakaida H, Umeda Y, Suzuki H. A case of arteriovenous fistula of the cauda equina fed by the proximal radicular artery: anatomical features and treatment precautions. Eur Spine J. 2018;27(3 suppl 3):281-286.

5. Namba K, Niimi Y, Ishiguro T, Higaki A, Toma N, Komiyama M. Cauda equina and filum terminale arteriovenous fistulas: anatomic and radiographic features. AJNR Am J Neuroradiol. 2020;41(11): 2166-2170.

6. Ohtonari T, Ota S, Nishihara N, et al. Arteriovenous fistula in a nerve root of the cauda equina fed by a proximal radiculo-medullary artery: a report of two cases. Interv Neuroradiol. 2011;17(2):217-223.

\section{Disclosures}

The authors report no conflict of interest concerning the materials or methods used in this study or the findings specified in this paper.

\section{Author Contributions}

Conception and design: Koyanagi. Acquisition of data: Koyanagi, Chiba. Analysis and interpretation of data: Koyanagi. Drafting the article: Koyanagi. Approved the final version of the manuscript on behalf of all authors: Koyanagi. Administrative/technical/material support: Imamura, Osanai.

\section{Correspondence}

Izumi Koyanagi: Hokkaido Neurosurgical Memorial Hospital, Sapporo, Japan. koyanagi@hnsmhp.or.jp. 